ARGONNE NATIONAL LABORATORY

9700 South Cass Avenue

ANL/EIS- - 20

Argonne, Illinois 60439

DE83 015979

ALTERNATIVES FOR MANAGEMENT OF WASTES GENERATED

BY THE FORMERLY DTILIZED SITES

REMEDIAL ACTION PROGRAM/

AND SUPPLEMIENT

by

T.L. Gilbert, J.M. Peterson, and R.W. Vocke Division of Environmental Impact Studies Argcnne National Laboratory

J.K. Alexander

U.S. Department of Energy

Oak Ridge Operations Office

Completed: December 1982

Revised: March 1983

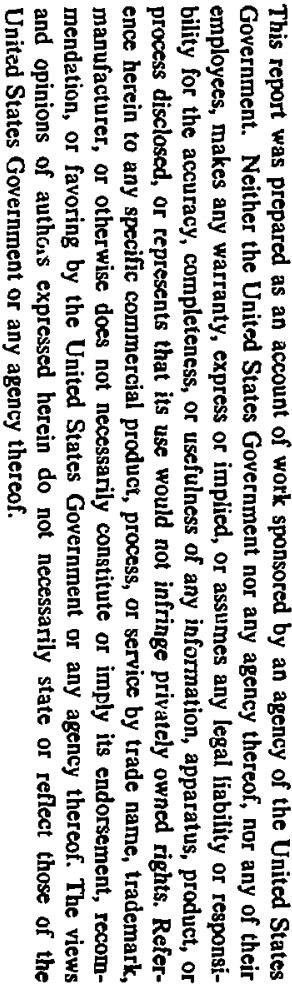

Prepared for

Formerly Utilized Sites Remedial-Action Program

U.S. Department of Energy

Oak Ridge Operations office

Oak Ridge, Tennessee 


\section{ALTERNATIVES FOR MANAGEMENT OF WASTES GENERATED \\ BY THE FORMERLY UTILIZED SITES \\ REMEDIAL ACTION PROGRAM \\ AND SUPPLEMENT}

by

T.L. Gilbert, J.M. Peterson, and R.W. Vocke Division of Environmental Impact Studies

Argonne National Laboratory

J.K. Alexander

U.S. Department of Energy

Oak Ridge Operations Office

\author{
Argonne Program Manager \\ Projeci Leader \\ Editor
}

Robert W. Vocke

Thomas L. Gilbert

Dimis J. Wyman 
The work presented in this report consists of an analysis of alternatives for management of wastes generated by the Formerly Utilized Sites Remedial Action Program (FUSRAP) of the U.S. Department of Energy. It consists of an analysis based on a preliminary assessment of the potential radiological impacts to the maximally exposed individual, and a revised analysis based on a revised assessment of these impacts. The original analysis was submitted as a manuscript in August 1982 for the Proceedings of the 1982 International Decommissioning Symposium and published in these proceedings in October 1982. Following submission of the manuscript, the radiological analysis was extended, revised, and issued in final form in March 1983.

The analysis of alternatives based on the original assessment of potential radiological impacts is presented in Sections 1 through 6 of this document. The text is the same as the published version (proceedings of symposium) except for minor editorial corrections and updating of references. The new findings are summarized in a Supplement and presented as Sections S1 through 56 of this document. The conclusions stated in the original manuscript remain valid. 


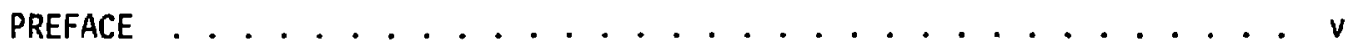

LIST OF FIGURES ................................ vii

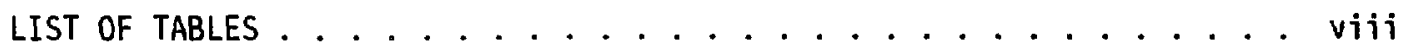

ALTERNATIVES FOR MANAGEMENT OF WASTES GENERATED BY THE

FORMERLY UTILIZED SITES REMEDIAL ACTION PROGRAM

1. INTRODUCTION ........................... . . . . . .

.. ISSUES . . . . . . . . . . . . . . . . . . . . 2-1

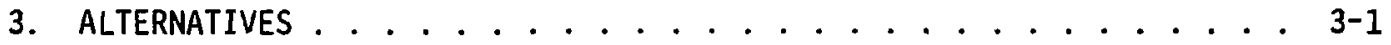

4. RADIOLOGICAL IMPACTS .................... . . . . . . .

5. COMPARISON OF ALTERNATIVES ................ . . . . .

6. REFERENCES .................... . . . . . . .

ALTERNATIVES FOR MANAGEMENT OF WASTES GENERATED BY THE

FORMERLY UTILIZED SITES REMEDIAL ACTION PROGRAM: SUPPLEMENT

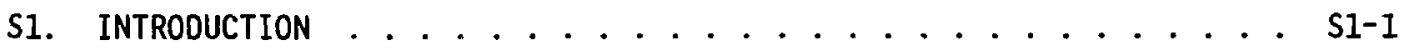

S2. RADIOLOGICAL IMPACTS ................ $\$$ \$2-1

S3. COST COMPARISONS .................. S3-I

S4. CONCLUSIONS ...............................

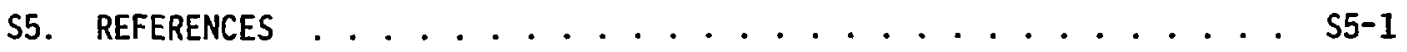




\section{FIGURES}

Figure

Page

1.1 Location of Sites That Require or May Require Remedial Action ................ 1-2

4.1 Major Pathways to the Maximal ly Exposed Individual . . . . 4-2

\section{TABLES}

Table

2.1 FUSRAP Waste Classification .............. 2-2

3.1 Disposal/Stabilization Alteratives for FUSRAP Wastes . . . . 3-2

4.1 Source-to-Dose Conversion Factors for Ra-226 and Decay

Products for the Maximally Exposed Individual at a

Representative FUSRAP Site .......... . . 4-4

5.1 Comparison of FUSRAP Waste-Disposal Alternatives . . . . . 5-2

S2.1 Mean Estimates of the Source-to-Dose Conversion Factors for the Maximally Exposed Individual at a Model FUSRAP Site for the Principal Radionuclides in the U-238 Decay Series . . S2-2

S2.2 Three Radiation Protection Standards and Generic Soi 1 Guidelines for FUSRAP Sites for the No-Action Alternative ... S2-3

S2.3 Ranking of Several Categories of Alternatives for Managing FUSRAP Wastes with Respect to Long-Term Radiological Impaicts to the Maximalily Exposed Individual . . . . . . S2-6

S3.1 Cost Comparison of Alternatives for Management of FUSRAP Wastes ............... S3-2 


\section{ALTERNATIVES FOR MANAGEMENT OF WASTES GENERATED}

BY THE FORMERLY UTILIZED SITES

REMEDIAL ACTION PROGRAM 


\section{ABSTRACT}

Alternatives for disposal or stabilization of the wastes generated by the U.S. Department of Energy's Formerly Utilized Sites Remedial Action Program (FUSRAP) are identified and compared, with emphasis on the long-term aspects. These wastes consist of soil material and rubble containing trace amounts of radionuclides. A detailed pathway analysis for the dose to the maximally exposed individual is carried out using an adaptation of the natural analogue method. Comparisons of the different alternatives, based on the results of the pathway analysis and qualitative cost considerations, indicate that, if the hazard is such that the wastes must be removed and disposed of rather than stabilized in place, disposal by immediate dispersal is preferable to containment, and containment followed by slow planned dispersal is preferable to containment without dispersal. 


\section{INTRODUCTION}

This report is based on an analysis for a problem that was solved--and reappeared. A new solution is being proposed and implemented. The history of the problem prompts one to ask: Will the same problem reappear again? Perspectives for dealing with this question, which have ramifications extending beyond the original problem, are presented herein.

The problem has its origins in programs conducted by the Manhattan Engineer District (MED) of the U.S. Army Corps of Engineers and its successor, the U.S. Atomic Energy Commission (AEC). These programs involved research, development, processing, and production of uranium and thorium by private contractors at different sites, some of which were privately or institutionally owned, during and shortly following World War II. Many of the sites became contaminated with radionuclides, mostly of natural origin, at low concentrations.

When the contracts for the MED/AEC activities were terminated, the sites involved were generally decontaminated according to health and safety criteria and guidelines applicable at that time, and released for unrestricted use. The problem reappeared because radiological criteria and guidelines for returning sites to unrestricted use became more stringent as a consequence of new insights provided by research on effr..'s of low-level radiation.

The new solution is embodied in the Formerly Utilized Sites Remedial Action Program (FUSRAP), initiated by the AEC in 1974 and now being planned and implemented by the U.S. Department of Energy (DOE). The program objective is to decontaminate selected sites to permit their unre-iricted use or to stabilize and/or otherwise control residual radioactivity at the sites to meet current criteria for the protection of public health and safety. Thirty-rive sites have been identified to date as possibly requiring some form of remedial action (Figure 1.1) (U.S. Dep. Energy 1982a). Twenty-two of the sites have been formaliy designated as requiring such action.

The remedial action involves several steps: identification of the sites, decontamination and/or control of the contamination, disposal and/or stabilization of the radioactive residues, compliance with legal and regulatory requirements, and certification of the sites for appropriate future use. The focus of this paper is the long-term aspects of disposal and/or stabilization of the radioactive residues, which consist mainly of soil material and rubble containing trace amounts of radionuclides.

Unexpected future developments were the nemesis of the original cleanup effort. Given the cloudiness of our crystal balls for peering into the future, these developments remain the primary hazard for renewed efforts to find a "permanent" solution. The unexpected cannot be extrapolated from the past; that is why it is unexpected. But we are capable of a limited amount of forgsight, and we can minimize, even if we cannot eliminate, upsetting unexpected developments by examining the long-term consequences to the best of our ability. 


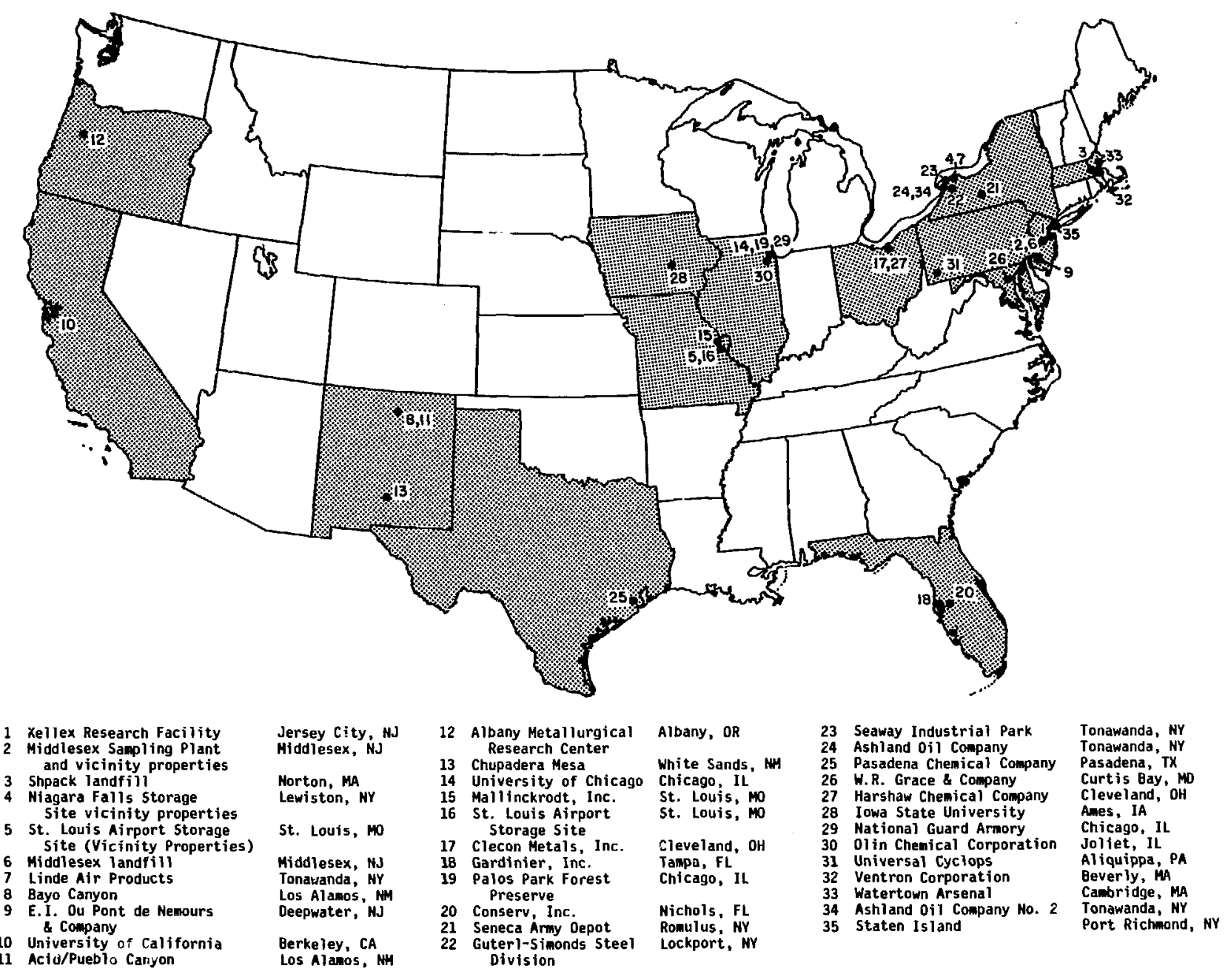

Figure 1.1. Location of Sites That Require or May Require Remedial Action. Source: U.S. Department of Energy (1982a). 
The long-term consequences are also a matter of regulatory concern. A key provision of the National Environmental Policy Act (NEPA) is to "... fulfill the responsibilities of each generation as trustee for succeeding generations" (P.L. 91-190, Sec. 101(b)(1)). The Council on Environmental Quality requires an environmental impact statement to address "... the relationship between short-term uses of man's environment and the maintenance and enhancement of long-term productivity, and any irreversible or irretrievable commitments of resources which would be involved ..." (40 CFR 1502.16).

A definition of long-term is not provided; in the absence of qualification, one must infer that no limits were intended. In a recent NRC/DOE/EPA agreement on human intrusion standards regarding high-level-waste repositories, the proposed language is "... that the federal government is to be committed to maintain passive, permanent controls for as long as civilization exists" (Anon. 1982), which suggests that long-term extends to the end of civilization. The uncertainties in predictions of the consequences of different wastedisposal alternatives would be fairly large by that time, but such difficulties do not eliminate the problem or the need to gain and apply as much foresight as we are able.

The essence of the problem is to identify suitable alternatives for disposal/stabilization of FUSRAP wastes. Alternatives available range from no action (which would require a finding that there were no significant public health or safety hazards) through development of elaborate regional disposal sites. The initial task is, clearly, to establish the magnitude of the public health and safety hazards. The outcome of this initial task does not lead to an unequivocal identification of the level of action needed. An objective analysis of the radiological hazards of FUSRAP wastes indicates that they are quite low, less than other hazards that the public accepts as the price of the amenities of modern living (U.S. Dep. Energy 1983). Current regulations do not, however, permit the hazards to be disregarded as being insignificant.

The selection of a preferred disposal alternative is further complicated by the fact that if a hazard exists, it will exist for a long time. Thus, any solution to the problem of disposal of FUSRAP wastes (and similar waste forms) must address the following two characteristics: the radiological hazards are very low and the hazard duration is very long. It is important to consider these characteristics in tandem. Emphasis on the very low radiological hazards without due consideration of the long duration, or on the long duration without due consideration of the very low radiological hazards, can lead to a distorted view of the issues that must be taken into account in selecting waste-disposal options.

The problem of selecting a waste-disposal alternative is a problem in benefit/cost/risk analysis. A thorough analysis would cover economic and social benefits, economic costs, public health and safety risks, and other environmental impacts. Analysis of the long-term tradeoffs presents interesting and difficuit problems that are not normally encountered in benefit/ cost/risk studies. Such comprehensive study, although clearly needed, is beyond the scope of this work, which is limited to an identification of the reasonable alternatives, a preliminary analysis of a few of the major environmental impacts and issues that should be considered in selecting an alternative, and a preliminary comparative assessment of the alternatives with respect to the dominant issues. 


\section{ISSUES}

The prior and underlying issue on which all other issues are contingent is the existence, magnitude, and duration of the radiological impacts from the residual radioactivity at FUSRAP sites. The general source terms for the radiological impacts are summarized in Table 2.1. The tetal volume of contaminated material is estimated to be about $440,00 \mathrm{~J} \mathrm{~m}^{3}$, of which about $90 \%$ is from uranium ore handling and processing operations. The principal hazard at most sites is from Ra-226 and its short-lived decay products; the duration of the hazard is determined primarily by the parent radionuclide U-238 or its decay product Th-230. Radiological surveys indicate that typical average radionuclide concentrations $1 \mathrm{ie}$ in the ranges of $20-200 \mathrm{pCi} / \mathrm{g} \mathrm{U}-238$ and $50-500 \mathrm{pCi} / \mathrm{g}$ Th-230 and Ra-226, with localized hot spots that exceed these averages by a factor of 10 to 100 . The contaminated regions range, typically, from 0.4 to 4 ha in area and from 0.1 to $3 \mathrm{~m}$ in depth, with a few sites where the contamination is limited to buildings (Argonne Nat?. Lab. 1982).

The magnitude and duration of the radiological hazard of FUSRAP wastes can be placed in perspective by comparison with other waste forms. The average concentration of all radionuclides in FUSRAP wastes is smaller than in mill tailings by a factor of about 5 , and the total volume of FUSRAP wastes (estimated as of June 1982) is smaller than the total volume of mill tailings (as of 1979) by a factor of about 200 (U.S. Nucl. Reg. Comm. 1980; Argonne Nat1. Lab. 1982). The average total concentration of all radionuclides in FUSRAP wastes is smaller than the initial concentration in commercial low-level radicactive wastes (LLW) by a factor ranging from about $10^{3}$ to over $10^{9}$. The total volume of FUSRAP wastes is larger than the annual volume of LLW generated in the United States (as of 1979) by a factor of about 5 (U.S. Dep. Energy 1980; Argonne Nat1. Lab. 1982).

The hazard duration for FUSRAP wastes and mill tailings is comparable. The principal radionuclides in mill tailings are Th-230 and its decay products; however, the concentration of residual U-238 in mill tailings is comparable to, and often greater than, the concentration of U-238 in FUSRAP wastes. Most of the radioactivity in commercial LLW decays within 500 years or less; proposed regulations governing the near-surface disposal of radioactive wastes impose restrictions with the intent that "... at the end of the 500 year period, remaining radioactivity will be at a level that does not pose an unacceptable hazard to an intruder or to public health and safety" (proposed 10 CFR $61.7(\mathrm{~b})(5))$. It should be noted, however, that the concentration of U-238 in industrial wastes from nuclear fuel fabrication plants, which are disposed in commercial near-surface disposal sites, is about $2000 \mathrm{pCi} / \mathrm{g} \mathrm{com-}$ pared with 20-200 pCi/g for FUSRAP wastes (U.S. Dep. Energy 1980; Argonne Nat1. Lab. 1982).

Once the existence of a radiological public health and safety hazard-however smal1--has been established or perceived to exist by a significant 
Table 2.1. FUSRAP Waste Classification

\begin{tabular}{lll}
\hline $\begin{array}{c}\text { Source of } \\
\text { Contamination }\end{array}$ & \multicolumn{1}{c}{ Primary Contamination } & $\begin{array}{c}\text { Half-Life of } \\
\text { Parent } \\
\text { Radionuclide }\end{array}$ \\
\hline $\begin{array}{c}\text { Uranium ore handling } \\
\text { and sampling }\end{array}$ & Uranium-238 and decay products & $4.5 \times 10^{9}$ years \\
$\begin{array}{l}\text { Uranium ore processing: } \\
\text { Product }\end{array}$ & Uranium-238 and decay products & $4.5 \times 10^{9}$ years \\
Residue (tailings) & Thorium-230 and decay products & 77,000 years \\
$\begin{array}{l}\text { Uranium salt/metal } \\
\text { processing }\end{array}$ & Uranium-238 and decay products & $4.5 \times 10^{9}$ years \\
$\begin{array}{l}\text { Thorium processing } \\
\begin{array}{l}\text { Nuclear weapons and/or } \\
\text { disposal sites }\end{array}\end{array}$ & $\begin{array}{l}\text { Thorium-232 and decay products } \\
\text { Fission products and possibly }\end{array}$ & $1.4 \times 10^{10}$ years \\
Miscelianeous & $\begin{array}{c}\text { Tritium and uranium-238 decay } \\
\text { products }\end{array}$ & Variable \\
\hline
\end{tabular}

Source: Argonne National Laboratory (1982).

number of people, other issues arise arid must be addressed. A survey of the issues and concerns related to LLW disposal that have appeared in the literature indicates that the major issues, other than radiological, are socioeconomic (primarily economic costs, public attitudes and perceptions, and land use), institutional (primarily regulatory), engineering and management, and questions regarding risk and uncertainty (Robinson and Gilbert 1982). Some of these issues can be expected to remain for as long as the hazard persists, e.g., costs (of any long-term surveillance, monitoring, and maintenance), public attitudes and perceptions, land use and land values, and regulatory matters. Preliminary generic assessments of the most important impacts, other than costs, have been made in order to determine what might be done to take into account the long-term aspects. As one might expect, there is very little that can be done because the uncertainties in impact predictions, other than the rate of hazard diminishment by radioactive decay, become so large beyond the short-term that one can only jist the credible possibilities and estimate bounds. It appears that the best that one can do in addressing the long-term aspects of waste disposal is to assess the long-term radiological impacts and also the continuing costs for surveillance, monitoring, and maintenance. For the purposes of this study, short-term is defined to be the time to completion of disposal activities or site closure (about 10 to 30 years); long-term is defined to be from the end of short-term to the end of civilization. 


\section{ALTERNATIVES}

The generic alternatives presented here are for waste disposal/stabilization and are intended to be final actions. Disposal/stabilization, however, does not preclude the possibility that future action could be required.

A systematic multilevel classification scheme that groups the alternatives into categories in a logical manner is presented in Table 3.1. The first-level alternatives (no action, onsite containment, offsite containment, and offsite immediate dispersal) are chosen to correspond to the sequence of steps involved in the decision-making process for FUSRAP. The no-action alternative would be adopted as a permanent option only if the public health and safety hazard from radioactive contamilation were found to be acceptable.

The second-level classification for the containment categories is based on consideration of the duration of the radiological hazard of FUSRAP wastes (thousands to billions of years). Containinent without dispersal until the hazard disappears by radioactive decay is, therefore, possible only if nearperpetual surveillance, with monitoring and corrective action as necessary, is assumed. In view of the considerable potential total cost, the commitment and burden placed on future generations, and the large uncertainty as to whether a commitment to maintain the integrity of a disposal site can be canried out, the concept of containment with a planned future dispersal rate (i.e., a rate such that the environmental concentrations of radionuclides from the wastes do not exceed acceptable levels) is introduced. A distinction is made between future planned dispersal with and without monitoring, due to future costs. offsite containment opens up a wider range of possiblities for third-level alternatives than does onsite containment.

Sites at accessible locations will be subject to at least minimal surveillance throughouc the long-term; it is, therefore, reasonable to assume that monitoring and corrective action would occur if the need arose. The corrective action would depend on whether the intent was to prevent dispersal or keep the rate of dispersal below some acceptable level; this intent could change with time. Thus, accessible sites have been placed in second-level categories of containment with monitored, planned future dispersal or containment without future dispersal.

The short-term distinction between containment without future dispersal and containment with monitored, planned future dispersal is not large for those alternatives that can be placed in either category (i.e., above-surface cuntainment, near-surface containment, and intermediate-depth containment). They relate primarily to planning and designing of the containment structure. In the former case, design features that facilitated future maintenance would be emphasized. In the latter case, the rate of migration would be taken into account and the design would be chosen so that this rate would not exceed a design level. The design level would be a compromise between: (1) the need 
Table 3.1. Disposal/Stebilization Alternatives* for FUSRAP Wastes

No action

Onsite containment

Containment without future dispersal

Above-surface containment

Near-surface containment

Containment with monitored, planned future dispersal

Institutional controls only

In-situ stabilization

Above-surface containment

Near--surface containment

Offsite containment

Containment without future dispersal

Above-surface containment

Near-surface containment

Intermediate-depth containment

Containment with monitored, planned future dispersal

Above--surface containment

Construction use

Near-surface containment

Intermediate-depth containment

Containment with unmonitored, planned future dispersal

Containerized ocean disposal

Disposal in deep geologic structures

Offsite immediate dispersa?

Ocean dispersal

Land dispersal

*No action - site released for unrestricted use.

Institutional controls orily - actions limited to control of access and use by regulatory means with no physical action.

In-situ stabilization - stabilization of wastes in place.

Above-surface containment - abovegrade emplacement of wastes in an engineered structure.

Near-surface containment - land disposal in or within the upper 15-20 m of the earth's surface.

Intermediate-depth containment - land disposal within 20-100 $\mathrm{m}$ of the earth's surface. 
to keep the release rate low enough to ensure that the radionuclide concentrations in the environment did not exceed acceptable limits and (2) the desirability of having a release rate that was high enough to disperse the radionuclides in a controlled manner before the containment barriers became degraded to the point that uncontrolled release might occur.

The long-term distinction between the two cor, "nment categories is greater. Surveillance and monitoring would be nee in for both categories. Periodic corrective action, with a resultant cumulaitive expense that could become quite high, would be inevitable for containment without future dispersal. A properly designed and constructed disposal facility for containment with monitored future planned dispersal might not require any corrective action, so that the cumulative future cost could be much less.

Monitoring may not be feasible for alternatives such as containerized ocean disposal and disposal in deep geologic structures. These alternatives are placed in the second-level category--containment with unmonitored planned future dispersal. They are, in general, distinguished by disposal locations that are far removed from human accessibility, so that monitoring would be unrecessary. Any radionuclides that might migrate from the source to an exposure point would be diluted to below background contributions from other natural sources before reaching a location where human exposure might occur.

The third-level classification for containment categories deals with finer distinctions between the second-level classification and approaches the point of identifying specific alternatives, although even at this level the list must be regarded as a set of categories rather than specific alternatives. (Sperific alternatives for most categories in Table 3.1 are discussed in the literature [Macbeth et al. 1978, 1979; U.S. Nuc]. Reg. Comm. 1981; U.S. Dep. Energy 1982b].) Some third-level containment alternatives, such as institutional controls only and in-situ stabilization, do not provide barriers with sufficient integrity to be suitable for permanent maintenance. These alternatives, therefore, are included only in the second-level category of containment with planned future dispersal.

The immediate-dispersal alternatives (ocean dispersal and land dispersal) do not require near-perpetual caretaker activites because radionuclides are dispersed immediately to near-background concentrations.

In analyzing disposal alternatives for FUSRAP wastes, it is necessary to be cognizant of the compatibility of waste form with disposal alternative. FUSRAP wastes are basically soil material and rubble containing trace amounts of radionuclides. These wastes are in a bulk form which would make dispersal very feasible. Should the containment alternatives be chosen, either with or without planned future dispersal, some form of waste modification may be appropriate. Waste modification can include anything from use of a standard waste-disposal container to immobilization through fusion processes. Wasteform modification would be a practical means of adjusting the rate of future dispersal to ensure that the levels of radicactivity do not exceed a specified value. 


\section{RADIOLOGICAL IMPACTS}

Two categories of radiological impacts can occur: occupational and general public. Occupational doses are short-term concerns that are no different from, and expected to be less than, occupational doses for currently operating near-surface disposal-sites; they will not be considered here. The items of concern are the individual and collective radiation doses to the general public in the long-term, especially the dose to the "maximally exposed individual". Annual short-term doses to the public, whether individual or collective, will generally be less than the corresponding long-term doses.

The potential radiological impacts depend on the condition of the disposal site, on the restrictions maintained for use of the site, and on the patterns of human activity associated with use of the site. All estimates of future radiological impacts are contingent on a "scenario" that defines these conditions. A number of scenarios were considered, including those used in previous studies (U.S. Nucl. Reg. Comm. 1981). An Intruder-Agriculture (IA) scenario was selected for the analysis for the maximally exposed individual.

In the IA scenario a family, unaware of the presence of the wastes, makes use of the site for a family farm. Specifications for the scenario include: the FUSRAP wastes are unprotected by any soil or other cover; the house, farmyard, family garden, pasturage for a milk cow and animals used for meat, and a farm pond used for livestock water and to raise fish for family consumption are all located in the contaminated area; and the family obtains its drinking water from a well at the edge of the contaminated area on the downgradient side. The scenario also assumes that a small child will ingest soil from the contaminated area.

The IA scenario is improbable, but not incredible, except for those few sites in which the contamination is entirely in an existing structure and there is no ground contamination. It satisfies two key requirements: no credible scenario that would lead to a larger individual dose was found, and a defensible basis for asserting that the IA scenario would not occur could not be found. It is applicable both to the no-action alternative and, in the long-term if records of site use for waste disposal are lost, to all nearsurface stabilization/disposal alternatives. It provides a base case that can be used as a starting point for a comparative analysis of the impacts of waste-disposal alternatives.

The nine major pathways shown in Figure 4.1 were identified, and the source-to-dose $(D / S)$ conversion factors for each pathway were calculated for radionuclides of the U-238 series. A calculation by means of standard methods in common use was done first; the results of this calculation were then corrected for cumulative errors from the many different models, data, and assumptions involved in a detailed environmental pathway analysis by means of an adaptation of the natural analogue method introduced by Cohen and Smith (1982). 


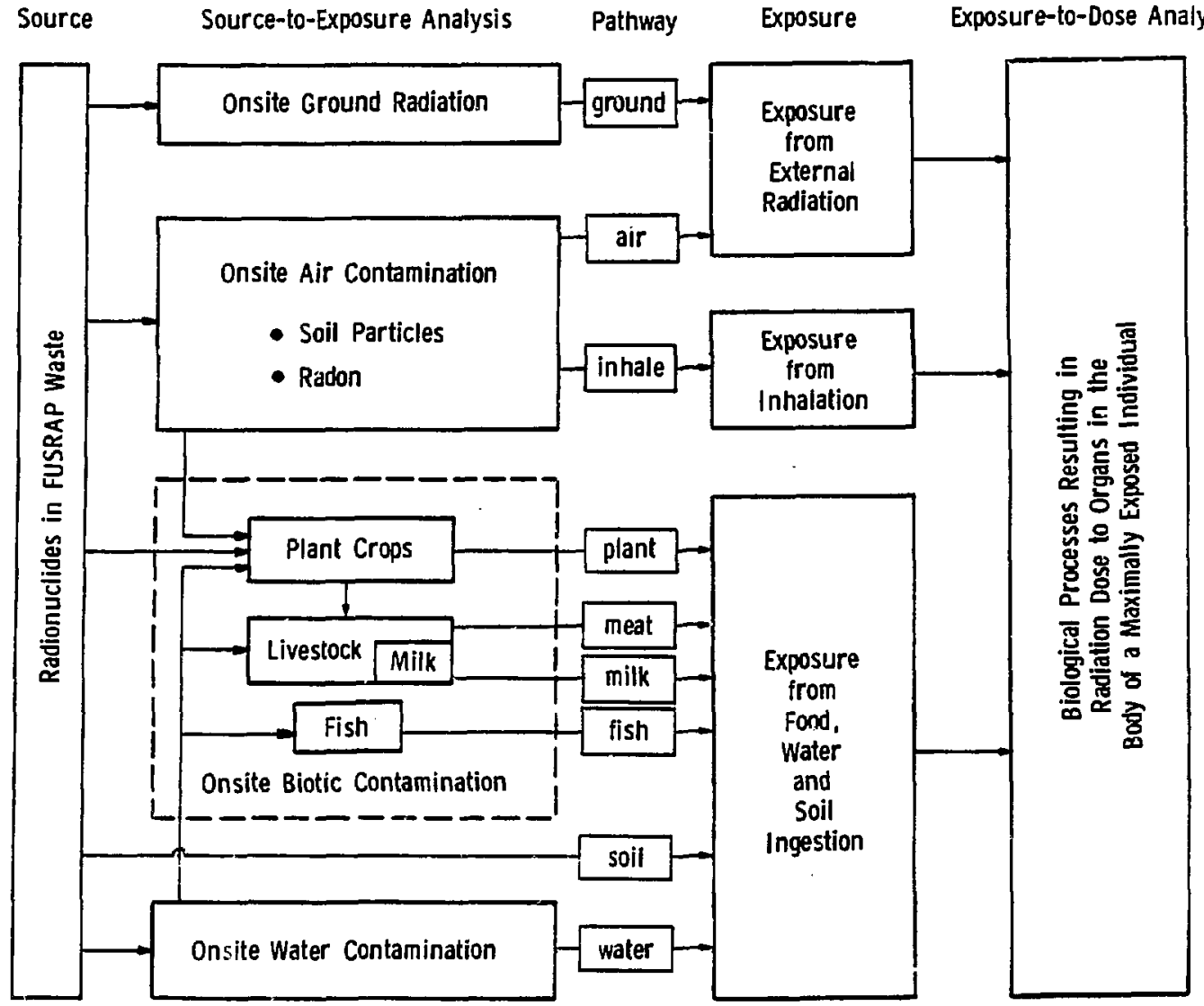

Figure 4.1. Major Pathways to the Maximally Exposed Individual. Source: Gilbert et al. (1983).

Application of the natural analogue method is the crucial part of the analysis and involves two steps. One step is a calculation, using the same methods, of $D / S$ factors for an average individual for a hypothetical FUSRAP site in which the contaminated area extends over a sufficiently large area to obtain source terms and dispersion machanisms that are the same as for naturally occurring radionuclides. The other step is a calculation of average $\mathrm{D} / \mathrm{S}$ factors for naturally occurring ragdionuclides using data on average soil concentrations, radionuciide intake by ingestion, and resulting internal body burdens. The ratios of the $D / S$ factor obtained from the second step to those obtained from the first step provide correction factors that can be applied to the calculated $D / S$ factors for a maximally exposed individual at a representative FUSRAP site in order to obtain more realistic values. The $D / S$ factors obtained in this manner for Ra-226 and decay products, based on a preliminary 
assessment (unpublished)* of the radiological impacts from FUSRAP wastes, are tabulated in Table 4.1. (See Table S2.1, Section S2, for D/S factors based on the final assessment.)

The indoor working level (WL) for radon inhalation, based on modeling and available data for working levels in various buildings, is estimated to be $0.0009 \mathrm{WL} /(\mathrm{pCi} / \mathrm{g})$ relative to the concentration of $\mathrm{Ra}-226$ in the FUSRAP wastes. **

If the $D / S$ factors in Table 4.1 are applied to the current $D O E$ radiation protection standards for the maximum permissible indiyidual doses in uncontrolled areas (which are 500 and $1500 \mathrm{mrem} / \mathrm{yr}$ for the whole body and bone, respectively) in order to obtain generic soil concentration limits for Ra-226, one obtains 18 and $9 \mathrm{pCi} / \mathrm{g}$, respectively. If the $E / S$ factor for radon is applied to the currently proposed EPA standard for buildings of $0.03 \mathrm{WL}$ (40 CFR 192), a limit of $33 \mathrm{pCi} / \mathrm{g}$ is obtained. It should be emphasized that these are generic limits based on a generic analysis that has been "calibrated" by means of natural analogue data and calculations.

The dose to the maximally exposed individual is the measure used in risk assessment for the high-consequence, low-probability events; it is the quantity of primary regulatory concern and reflects the risk most iikely to arouse public concern. The probability is difficult to determine and is not needed for comparative assessments of alternatives because it is the same for all aiternatives for which the IA scenario is applicable. It is quite low because the probability that the IA scenario will be realized is small and the number of individuals involved in the scenario is small. The measure used for risk assessment of the average events (which are dominated by low-consequence, high-probability events) is the population dose.

The population dose has been estimated for the no-action case for an assumed population of $2 \times 10^{6}$ individuals living within $80 \mathrm{~km}$ of the site. The annual bone dose in the long-term is estimated to be about 20 person-rem/yr for the entire population. In order to place this dose in perspective, it should be compared to the corresponding bone dose of about $3 \times 10^{5}$ person-rem/yr from natural background radiation. Thus, if no action were taken and there were no protective cover, the population dose from FUSRAP wastes would be abuut ten thousand times smaller than the natural-background population dose.

The radiological hazard from most FUSRAP wastes, those for which the primary contaminant is U-238 and its decay products, will not diminish appreciably by radioactive decay for billions of years. This does not, however, imply that the hazard is a permanent one. It can be eliminated by dispersal of the radionuclides until incremental concentrations in the environment are negligible compared to the natural background. The most likely mechanisms by which this may occur are erosion and leaching.

Erosion is likely to occur, primarily by water action. Water erosion rates can vary widely depending on the rainfall, slope, vegetative cover, and

\footnotetext{
*The preliminary assessment was based on an early draft (July 1982) 0; a pathway analysis by Gilbert et al. (1983).

$x:$ The value of $0.0009 \mathrm{WL} /(\mathrm{pCi} / \mathrm{g})$ is based on a preiminary assessment (see preceding footnote). The revised estimate is $0.0016 \mathrm{WL} /(\mathrm{pCi} / \mathrm{g})$.
} 
Table 4.1. Source-to-Dose $(D / S)$ Conversion Factors for Ra-226 and Decay Products for the Maximally Exposed Individual at a Representative FUSRAP Site*

\begin{tabular}{|c|c|c|}
\hline \multirow[b]{2}{*}{ Pathway } & \multicolumn{2}{|c|}{$\begin{array}{c}\text { Dose (mrem/yr) to } \\
\text { Maximally Exposed Individual } \\
\text { per pci/g of Ra-226 } \\
\text { in the Wastes } \star \star\end{array}$} \\
\hline & Whole Body & Bone \\
\hline \multicolumn{3}{|c|}{ External Radiation } \\
\hline Ground & 10 & 10 \\
\hline \multicolumn{3}{|l|}{ Air: } \\
\hline Dust & $1 \times 10^{-6}$ & $2 \times 10^{-6}$ \\
\hline Radon & 0.08 & 0.09 \\
\hline \multicolumn{3}{|c|}{ Internal Radiation } \\
\hline \multicolumn{3}{|c|}{ Inhalation: } \\
\hline Dust & 0.004 & 0.05 \\
\hline Radon & - & 0.1 \\
\hline \multicolumn{3}{|c|}{ Ingestion: } \\
\hline Water & 4 & 35 \\
\hline Plant & 9 & 80 \\
\hline Meat & 0.06 & 0.6 \\
\hline Milk & 0.2 & 1.4 \\
\hline Fish & 0.4 & 4 \\
\hline Soil & 4 & 39 \\
\hline TOTAL & 28 & 170 \\
\hline
\end{tabular}

*For exposed homogeneous wastes, i.e., in the absence of protective cover but without "hot spots".

**The $D / S$ factors in this table are based on an early draft (unpublished) of an assessment of the radiological impacts from FUSRAP wastes (Gilbert et al. 1983). In the revised assessment, the whole-body dose is $21 \mathrm{mrem} / \mathrm{yr}$ rather than $28 \mathrm{mrem} / \mathrm{yr}$, and the bone dose is $87 \mathrm{mrem} / \mathrm{yr}$ rather than $170 \mathrm{mrem} / \mathrm{yr}$ (see Table S2.1, Section S2). 
other factors; a typical rate for climax vegetation on a $5 \%$ siope in the East is about $0.05 \mathrm{~mm} / \mathrm{yr}$ (Knight 1982). This rate would disperse all wastes at a representative FUSRAP site in 30,000 years. Other conditions, such as rowcrop agriculture and a greater slope, or formation of gullys, could decrease the time by as much as a factor of 100 or more. Soil or clay cover would increase the time by a factor proportional to the cover thickness.

Leaching will lead to an exponential decrease of the radionuclide concentrations in the wastes. Leaching rates may vary over several orders of magnitude; theie is very little data for them, and the mechanisms are poorly understood. Estimates of tine for the radionuclide concentrations in the wastes to decrease by a factor of one-half by leaching alone vary from somewhat less than 1,000 years to more than 100,000 years (Gilbert et a1. 1983).

For a carefully planned site, dispersion by natural mechanisms could eventually eliminate the hazard while maintaining the incremental increase in offsite radionuclide concentrations to values that were comparable to or less than the prevailing background levels. In a poorly planned site, the dispersion might lead only to transport of the radionuclides offsite without adequate dilution.

A key issue for comparing alternatives is the reduction in the radiological hazards for waste-disposal alternatives in which the waste is covered and the cover is maintained (or erosion does not occur). If the cover is sufficient to prevent crop roots from reaching the contaminated material, it will effectively eliminate the contributions from most of the pathways by reducing them to background levels. The dose contributions from external ground radiation; radon emanation; plant uptake; meat, milk, and fish contamination; and soil ingestion will all be reduced to background levels. The only remaining pathway of any significance is the water ingestion pathway.

A small leach rate ard a large radionuclide migration rate in the underlying aquifer are the favorable conditions for reducing the $\mathrm{D} / \mathrm{S}$ factor for the water pathway. This reduction can be accomplished by reducing the ratio of the retarded permeability of the cover to the retaided permeability of the aquifer. (The retarded permeability is the hydraulic conductivity divided by the product of the retardation factor and effective porosity.) A reduction of many orders of magnitude can be achieved if this ratio can be made smal1--and kept small by proper maintenance of the cover. (A clay liner can also be used, but must be designed with care because a liner that is less permeable than the cover can lead to a "bathtub effect" in which the clay-lined disposal trench fills with water and overflows, thereby increasing the leach rate.) It should be noted, however, that a failure of the cover that affected the water pathway (e.g., by cracks or animal burrows that permit water to reach the waste and increase the leach rate) is much less likely to be detected and corrected than a failure that would affect the other pathways (e.g., by erosion that reduced the cover thickness to the point where roots could reach the waste).

The dispersal alternatives, if properly carried out to dilute the contamination to near-background levels, would reduce the the maximally exposed individual dose to an incremental value that was less than the average natural background dose. Land dispersal would increase the incremental population dose (by a factor of about 3 ), but it would still be insignificant compared to background. 


\section{COMPARISON OF ALTERNATIVES}

The radiological impacts, costs, and requirements for future actions following disposal of the FUSRAP wastes for the various alternatives are given in Table 5.1. Since detailed analyses of these alternatives have not yet been performed, this comparison is by necessity qualitative. For purposes of comparison, the baseline alternative is taken to be near-surface, offsite containment without future dispersal. The only radiological impacts (doses) considered are those incurred in the long-term by the maximally exposed individual. The population doses will all be insignificant compared to background (see Section 4). The costs are divided into short-term costs required to implement the alternative and long-term costs associated with future surveillance, monitoring, and maintenance to ensure the integrity of the disposal site.

The large uncertainties are taken into account differently for radiological impacts and cost estimates in order to obtain conservative estimates. For radiological impacts, it is assumed that institutional controls can fail and that the IA scenario is applicabie at any time after 1000 years. For costs it is assumed that institutional controls do not fail, so that surveillance, monitoring, and maintenance continue throughout the long-term or unti] the radionuclides are dispersed. If, therefore, the maximum radiological impacts were realized, the maximum costs would not be, and vice versa.

The results of Table 5.1 can be summarized as follows:

- Near-surface containment without dispersal would be one of the more expensive alternatives due to the requirement of an active surveillance, monitoring, and maintenance program, and would not result in a cost-commensurate radiation dose reduction.

- The immediate-dispersal options are preferable to the containment options in terms of lower costs and radiological impacts to the maximally exposed individual.

It should be noted that if it were possible to ensure the integrity of the engineered barriers for the containment options ad infinitum, these options woula have the lowest radiological impact but would be very expensive. 
Table 5.1. Comparison of FUSRAP Waste-Dispesal ATternatives

\begin{tabular}{|c|c|c|c|c|c|}
\hline \multirow[b]{2}{*}{ Alternative } & \multirow{2}{*}{$\begin{array}{l}\text { Long-Term } \\
\text { Radiological } \\
\text { Impacts* }\end{array}$} & \multirow{2}{*}{$\begin{array}{l}\text { Future } \\
\text { Commi tmeiri } \\
\text { Required*t }\end{array}$} & \multicolumn{3}{|c|}{ Costs } \\
\hline & & & $\begin{array}{l}\text { Sinu:-t- } \\
\text { Term† }\end{array}$ & $\begin{array}{l}\text { Long- } \\
\text { Termit }\end{array}$ & Total \\
\hline No Action & Same & Nune & Lower & None & Lower \\
\hline \multicolumn{6}{|l|}{ Onsite Containment } \\
\hline \multicolumn{6}{|l|}{ Without Future Dispersal: } \\
\hline Above-surface containment & Same & SMM & Lower & Same & Lower \\
\hline Near-surface containment & Same & SMM & Lower & Same & Lower \\
\hline \multicolumn{6}{|c|}{ With Monitored Future Planned Dispersal: } \\
\hline Institutional controls only & Same & SMM & Lower & Lower & Lower \\
\hline In-situ stabilization & Same & SMM & Lower & Lower & Lower \\
\hline Above-surface containment & Same & SMM & Lower & Lower & Lower \\
\hline Near-surface containment & Same & SMM & Lower & ower & Lower \\
\hline \multicolumn{6}{|l|}{ Offsite Containment } \\
\hline \multicolumn{6}{|l|}{ Without Future Dispersal: } \\
\hline Above-surface containment & Same & SMM & Higher & Same & Hi gher \\
\hline Near-surface containment $\dagger_{\dagger} \dagger$ & - & SMM & - & - & - \\
\hline Intermediate-depth containment & Same & SMM & Higher & Higher & Higher \\
\hline \multicolumn{6}{|c|}{ With Monitored Future Planned Dispersal: } \\
\hline Above-surface containment & Same & SMM & Higher & Lower & Lower \\
\hline Construction use & Same & SMM & Lower & Lower & Lower \\
\hline Near-surface containment & Same & SMM & Same & Lower & Lower \\
\hline Intermediate-depth containment & Same & SMM & Higher & Lower & Lower \\
\hline \multicolumn{6}{|c|}{ With Unmonitored Future Planned Dispersal: } \\
\hline Containerized ocean disposal & Lower & None & Higher & None & Lower \\
\hline Deep geologic disposal & Lower & None & Higher & None & Lower \\
\hline \multicolumn{6}{|l|}{ Offsite Immediate Dispersal } \\
\hline Ocean Dispersal & Lower & None & Higher & None & Lower \\
\hline Land Dispersal & Lower & None & Higher & None & Lower \\
\hline
\end{tabular}

“Comparisons represent assessments of impacts (doses to maximally exposed individual) that could occur at any time over a period extending from breakdown of institutional controls until the wastes are completely dispersed by natural means. A "same" entry means "unable to differentiate within the limits of uncertainty."

${ }^{\star \star}$ SMM $=$ Surveillance, monitoring, and maintenance.

${ }^{\dagger}$ Short-term is a period following disposal that extends to completion of disposal activities or to site closure ( 10 to 30 years).

${ }^{\dagger+}$ Long-term extends from the end of short-term until the wastes are completely dispersed to concentrations well below background or until the end of civilization. Long-term costs are surveillance, monitoring, and maintenance costs.

${ }^{+\dagger}$ Alternative on which comparisons are based. 


\section{REFERENCES}

Anonymous. 1982. NRC, DOE and EPA agree on human intrusion standard. Nuclear Waste News 2(12).

Argonne National Laboratory. 1982. Methods for Assessing Environmental Impacts of a FUSRAP Property-Cleanup/Interim-Storage Remedial Action. ANL/EIS-16. Prepared for the Formerly Utilized Sites Remedial Action Program, U.S. Department of Energy, Oak Ridge, TN, by the Division of Environmental Impact Studies, Argonne National Laboratory, Argonne, IL.

Cohen, J.J., and C.F. Smith. 1982. Validation of Predictive Models for Geologic Disposal of Radioactive Waste via Natural Analogs, pp. 215-221. In David C. Kocher (ed.), Symposium on Uncertainties Associated with the Regulation of the Geologic Disposal of High-Level Radioactive Waste, Gatlinburg, TN, March 9-13, 1981. NUREG/CP-0022; CONF-810-372. March 1982.

Gilbert, T.L., P.C. Chee, M.J. Knight, J.M. Peterson, C.J. Roberts, J.E. Robinsor S.Y.H. Tsai, and Y.C. Yuan. 1983. Pathways Analysis and Radiation Dose Estimates for Radioactive Residues at Formerly Utilized MED/AEC Sites. ORO-832. Prepared for the Formerly Utilized Sites Remedial Action Program, U.S. Department of Energy, Oak Ridge Operations, Oak Ridge, TN, by the Division of Environmental Impact Studies, Argonne National Laboratory, Argorine, IL.

Knight, M.J. 1982. The Effect of Soil Erosion on the Long-Term Stability of FUSRAP Near-Surface Waste-Burial Sites. ANL/EIS-18. Prepared for the Formerly Utilized Sites Remedial Action Program, U.S. Department of Energy, Oak Ridge Operations, Oak Ridge, TN, by the Division of Environmental Impact Studies, Argonne National Laboratory, Argonne, IL.

Macbeth, P.J., D.E. Christensen, B.J. Thamer, and G. Wehmann. 1978. Screening of Alternative Methods for the Disposal of Low-Level Radioactive Waste. NUREG/CR-0308. Prepared for the Office of NuClear Material Safety and Safeguards, Washington, DC, by Ford, Bacon \& Davis Utah Inc., Salt Laka City, UT.

Macbeth, P.J., G. Wehmann, B.J. Thamer, and D.H. Card. 1979. Evaluation of Alternative Methods for the Disposal of Low-Level Radioactive Wastes. NUREG/CR-0680. Prepared for the Low-Level Waste Branch, U.S. Nuclear Regulatory Commission, Washington, DC, by Ford, Bacon \& Davis Utah Inc., Salt Lake City, UT. 
Robinson, J.E., and T.L. Gilbert. 1982. Scoping Survey of Perceived Concerns, Issues, and Problems for Near-Surface Disposal of FUSRAP Waste. ANL/EIS-17. Prepared for the Formerly Utilized Sites Remedial Action Program, U.S. Department of Energy, Oak Ridge, TN, by the Division of Environmenta] Impact Studies, Argonne National Laboratory, Argonne, IL.

U.S. Department of Energy. 1980. Understanding Low-Level Radioactive Waste. LLWMP-2. Low-Level Waste Management Program, EG\&G Idaho, Inc., Idaho Fal1s, ID.

U.S. Department of Energy. 1982a. Energy Systems Acquisition Project Plan (ESAPP), Formerly Utilized MED/AEC Sites Remedial Action Program (FUSRAP). Prepared by 0ak Ridge Operations Office for the Assistant Secretary of Nuclear Energy.

U.S. Department of Energy. 1982b. FUSRAP Waste Disposal Options Study. DOE/ OR/20722-3. Prepared by Bechtel National, Inc., Oak Ridge, TN. $3 \mathrm{v}$.

U.S. Department of Energy. 1983. Radiological Guidelines for Application to the DOE's Formerly Utilized Sites Remedial Action Program. ORO-831.

Oak Ridge Operations, Oak Ridge, TN.

U.S. Nuclear Regulatory Commission. 1980. Final Generic Environmental Impact Statement on Uranium Milling. NUREG-0706. Office of Nuclear Material Safety and Safeguards, Washington, DC.

U.S. Nuclear Regulatory Commission. 1981. Draft Environmental Impact Statement on 10 CFR Part 61, "Licensing Requirements for Land Dispósa? of Radioactive Waste." NUREG-0782. Office of Nuclear Material Safety and Safeguards, Washington, DC. $3 \mathrm{v}$. 
ALTERNATIVES FOR MANAGEMENT OF WASTES GENERATED BY THE FORMERLY UTILIZED SITES

REMEDIAL ACTION PROGRAM:

SUPPLEMENT 


\section{ABSTRACT}

This Supplement presents refinements of work that was reported at the 1982 International Decommissioning Symposium. The new material consists of revisions in the estimates of the predicted potential dose to the maximally exposed individual and a more detailed comparative assessment of the radiological impacts of alternatives for management of wastes generated by the U.S. Department of Energy's Formerly Utilized Sites Remedial Action Program (FUSRAP). 


\section{S1. INTRODUCTION}

Preliminary results of an analysis of alternatives for management of FUSRAP wastes were presented in a manuscript submitted in August 1982 for the Proceedings of the 1982 International Decommissioning Sympasium held in Seattle, Washington, on October 10-14, 1982 (Gilbert et al. 1982). This analysis has been extended and revised. The original manuscript is presented as Sections 1 through 6 of this document. The new findings are summarized in this Supplement as Sections S1 through S5. The conclusions stated in the original manuscript remain valid.

The changes presented in this Supplement are in the estimates of the radiological impacts from the radioactive residues in the soil materials at sites that have been identified for the Formerly Utilized Sites Remedial Action Program (FUSRAP) of the U.S. Department of Energy. The radiological impact assessments in the manuscript submitted in August 1982 were based on a draft version (unpublished), prepared in July 1982, of an analysis of the potential individual radiation doses from FUSRAP wastes. The radiological impact assessments in the supplement are based on the final version that was completed in March 1983 (Gilbert et al. 1983). 


\section{S2. RADIOLOGICAL IMPACTS}

The revised estimates of the radiological impacts are based on the $\mathrm{D} / \mathrm{S}$ conversion factors reproduced in Table S2.1. These factors are the ratio of the radiation dose rate $(D)$ in mrem/yr for the maximally exposed individual to the concentration $(S)$ in $\mathrm{pCi} / \mathrm{g}$ of a radionuclide present in the soil material of a typical FUSRAP site. The size of a typical contaminated region (waste field) is assumed to be $140 \mathrm{~m} \times 140 \mathrm{~m}$ in area and $1.5-\mathrm{m}$ deep. The $\mathrm{D} / \mathrm{S}$ factors correspond to the no-action alternative for a site with a waste field of this size exposed at the ground surface. The estimates are based on the IA scenario described in Section 4. Table S2.1 supersedes and replaces Table 4.1 of this document.

The source-to-dose conversion factors may be used to determine guidelines for the limiting concentrations of radionuclides in the soil. These guidelines are defined in such a manner that if a soil guideline is not exceeded, a specified exposure or dose limit is not likely to be exceeded. Listed in Table S2.2 are the soil guidelines that would apply to a model FUSRAP site under the no-action alternative for (a) current EPA building-cleanup regulations for indoor exposure to radon and (b) current DOE regulations for dose limits in uncontrolled areas.

The half-lives of the principal radionuclides are $4.5 \times 10^{9}$ years $(U-238)$, 77,000 years (Th-230), and 1,600 years $(\mathrm{Ra}-2<6)$. If all three principal radionuclides are present in the wastes in secular equilibrium, the rate of decrease in the concentration of all radionuclides will be controlled by the rate of decrease in the concentration of $U-238$, which is completely negligible insofar as any future reduction in the radiological hazards by radioactive decay is concerned. If the U-238 and U-234 are not present, then the concentration of Th-230 (and all of its decay products if they are, initially, in secular equilibrium with Th-230) will decrease to $91 \%, 41 \%$, and $0.01 \%$ of its initial value in $10,000,100,000$, and $1,000,000$ years, respectively. If Ra-226 is present without U-238 or Th-230, it will decrease to $65 \%$ and $1.3 \%$ of its initial value in 1,000 and 10,000 years, respectively. At most FUSRAP sites, Ra-226 is in near-secular equilibrium with Th-230 and thus the decrease in concentration of Ra-226 by radioactive decay is controlled by the rate of decay of Th-230.

If a radionuclide is present without decay products, then the time for its decay products to reach a given fraction of the activity concentration of the parent by ingrowth is equal to the time for the longest-lived decay product to be reduced by the complemeniary fraction by radioactive decay. Thus, if U-238 and U-234 are present without decay products,* the concentration of

*The times will be much longer for $U-238$ alone because the rate of ingrowth
will then be controlled by $U-234$, which has a half-life of 244,000 years. 
Table S2.1. Mean Estimates of the Source-to-Dose (D/S) Conversion Factors for the Maximally Exposed Individual at a Model FUSRAP Site for the Principal Radionuuclides in the U-238 Decay Series

\begin{tabular}{lccc}
\hline & \multicolumn{3}{c}{$\mathrm{D} / \mathrm{S}$ in (mrem/yr)/(pCi/g) } \\
\cline { 2 - 4 } $\begin{array}{l}\text { Radionuclide } \\
\text { and Organ }\end{array}$ & $\begin{array}{l}\text { External } \\
\text { Radiation }\end{array}$ & $\begin{array}{c}\text { Internal } \\
\text { Radiation }\end{array}$ & Total \\
\hline $\begin{array}{l}\text { U-238 } \dagger^{1} \text { : } \\
\text { Whole body }\end{array}$ & 0.1 & 2.4 & 2.5 \\
Bone & 0.1 & 20 & 20 \\
Whole lung & 0.08 & 0.7 & 0.8 \\
$\begin{array}{l}\text { Th-230 } \dagger^{2} \text { : } \\
\text { Whole body }\end{array}$ & 20 & & \\
Bone & 20 & 0.3 & 0.3 \\
Ra-226 $\dagger^{3}$ : & & 5 & 5 \\
Whole body & 10 & & \\
Bone & 11 & 11 & 21 \\
Whole lung & 9 & 76 & 87 \\
Bronchial epithelium ${ }^{4}$ & - & 28 & 37 \\
\hline
\end{tabular}

$\ddagger^{1}$ The total $\mathrm{D} / \mathrm{S}$ factor for $\mathrm{U}-238$ is the arinual external dose from $\mathrm{U}-238$, Th-234, Pa-234m, and U-234 plus the annual 50-year dose commitment from inhalation and ingestion of $\mathrm{U}-238$ and $\mathrm{U}-234$ per $\mathrm{pC} i / g$ of $\mathrm{U}-238$ in the wastes for the maximally exposed individual at a model FUSRAP site.

$\dagger^{2}$ The total $\mathrm{D} / \mathrm{S}$ factor for Th-230 is the annual 50-year dose commitment from inhalation and ingestion of $\mathrm{Th}-230 \mathrm{per} \mathrm{pCi} / \mathrm{g}$ of Th-230 in the wastes for the maximally exposed individual at a model FUSRAP site. The contributions from ingrowth of Ra-226 and its decay products are not included.

$\ddagger^{3}$ The total $\mathrm{D} / \mathrm{S}$ factor for Ra-226 is the annual external dose plus tne 50-year dose commitment from inhalation and ingestion of Ra-226 and all of its radioactive decay products ( $\mathrm{Rn}-222$, $\mathrm{Po}-212, \mathrm{~Pb}-214, \mathrm{Bi}-214, \mathrm{Po}-214, \mathrm{~Pb}-210, \mathrm{~B} \mathrm{j}-210$, and $\mathrm{Po}-210$ ) per $\mathrm{pCi} / \mathrm{g}$ of Ra-226 in the wastes for the maximally exposed individual at a model FUSRAP site.

$i^{4}$ The dose to the bronchial epithelium is primarily from inhalation of airborne decay products of $\mathrm{Rn}-222$. The ratio of the exposure, expressed as the radon working level (WL), to the concentration of Ra-226 in the wastes is estimated to be $\mathrm{WL} / \mathrm{S}=0.0016 \mathrm{WL} /(\mathrm{pCi} / \mathrm{g})$ indoors. 
Table S2.2. Three Radiation Protection Standards and Generic Soil Guidelines for FUSRAP Sites for the No-Action Alternative $\dagger^{1}$

\begin{tabular}{|c|c|c|}
\hline $\begin{array}{l}\text { Radiation } \\
\text { Protection Standard }\end{array}$ & Radionuclide & $\begin{array}{l}\text { Corresponding Generic } \\
\text { Soil Guidelines }(\mathrm{pC} i / g) \dagger^{2}\end{array}$ \\
\hline $\begin{array}{l}0.03 \text { WL radon decay product } \\
\text { exposuret }{ }^{3}\end{array}$ & Ra-226 & 19 \\
\hline \multirow[t]{3}{*}{$1500 \mathrm{mrem} / \mathrm{yr}$ bone dose $\dagger^{4}$} & $U-238$ & 75 \\
\hline & Th-230 & $300 \dagger^{5}$ \\
\hline & Ra-226 & 17 \\
\hline \multirow[t]{3}{*}{$500 \mathrm{mrem} / \mathrm{yr}$ whole-body dose $f^{4}$} & $u-238$ & 200 \\
\hline & Th-230 & $1700 \dagger^{5}$ \\
\hline & $\mathrm{Ra}-226$ & 24 \\
\hline
\end{tabular}

$\dagger^{1}$ If the radionuclide concentration in the soil at a model FUSRAP site does not exceed a generic soil guideline, then the exposure or dose is unlikely to exceed the exposure or dose from which the guideline is derived. The model site is chosen to represent a typical FUSRAP site.

$\dagger^{2}$ Calculated from radiation protection standards using the $D / S$ factors from Table S2.1.

$t^{3}$ U.S. Environmental Protection Agency standard: 40 CFR 192, Health and Environmental Standards for Inactive Uranium Mill Tailings (includes background).

$\dagger^{4}$ U.S. Department of Energy standard: Requirements for Radiation Protection, DOE Order 5480.1A, Chapter XI, August 1981 (above background).

$t^{5}$ This guideline applies only for the near term, before any significant ingrowth of Ra-226 has occurred. The risk from Th- 230 will be determined by the concentration of its decay products ( $R a-226$ and subsequent decay products) for time periods greater than about 100 years. The soil guidelines for Th-230 in the long term are the same as the soil guidelines for Ra-226.

Th-230 (and all of its decay products) will attain $9 \%, 59 \%$, and $99.99 \%$ of the concentration of $11-234$ in $10,000,100,000$, and 1,000,000 years, respectively; and if Th-230 is present alone, the concentration of Ra-226 and all of its decay products wi 11 reach $35 \%$ and $98.7 \%$ of the concentration of $T h-230$ in 1,000 and 10,000 years, respectively.

If measures to prevent erosion or provide for controlled dispersal are not implemented, uranium ore and ore-processing residues at FUSRAP sites-which constitute the major part of FUSRAP wastes--will remain hazardous unt il they are dispersed by erosion or removed by leaching and dispersed. The time 
for complete dispersal by erosion to occur at a typical FUSRAP site is estimated to be about 30,000 years for a site with a $5 \%$ slope and climax growth (Knight 1982; Gilbert et al. 1983). This wculd decrease to about 4,000 years if the ground cover were permanent pasture and could be as short as about 500 years if the land were used for row-crop agriculture. The above ranges are based on sheet or rill erosion; the times could be much shorter if gully erosion occurred. These conclusions apply to U-238 decay series radionuclide: for which the diffusion model is the most realistic description of the leachil process. For man-made radionuclides that are present at a few sites and for which the ion-exchange model is more realistic, some will be eliminated by radioactive decay in a few hundred years (e.g., $\mathrm{H}-3, \mathrm{Sr}-90$, and $\mathrm{Cs}-137$ ); others may be removed by leaching.

The estimated time for dispersal by leaching into the groundwater depend: on the leaching mechanism. If the leaching mechanism is by ion exchange of radionuclides adsorbed on the surface of soil particles, which is the mechanism by which radionuclides migrate through an aquifer, the $D / S$ factors in 1,000 years would be reduced to about $10 \%$ of the initial value for $\mathrm{U}-238$ and to about $20 \%$ of the initial value for Ra-226. The reduction for Th-230 would be negligible. In 10,000 years, the reduction would still be negligible for Th-230 whereas the $\mathrm{D} / \mathrm{S}$ factors for U-238 and Ra-226 would be reduced to less than 1\% of their initial values (except for the water pathway, for which the D/S factor does not reach a maximum value and start to decrease until after the radionuclides have been leached from the waste field).

If the leaching is by a diffusion process, wich diffusion coefficients comparable to those obtained from laboratory measurements on ore-contaminated soils, the leach rates would be slower by a factor of 10-4 or less, and the reduction in the $\mathrm{D} / \mathrm{S}$ factors from leaching would be negligible in a period of 10,000 years.

The leaching rate at FUSRAP sites contaminated by ore or ore-processing residues is expected to be closer to the rate predicted by the diffusion mode than to the rate predicted by the ion-exchange model, but somewhat faster because laboratory measurements do not take into account the effect of some o1 the biological, chemical, and physical processes that occur under field conditions but not under laboratory conditions.

The three critical factors that enter into all comparative assessments of FUSRAP waste management alternatives are: the effectiveness of institutional controls; the thickness of clean material placed over the wastes; and the permeability of the cover material. Other factors are of major importance only insofar as they arfect these three factors.

Institutional controls are important for precluding the occurrence of intruder scenarios. Inadvertent intrusion would not occur as long as the controls remained in effect. Compared to the no-action alternative, this would reduce exposure to the radionuclides by one to two orders of magnitude by eliminating or greatly reducing all pathway contributions except the drinking water pathway for a near-site well. The dose to a transient inadvertent intruder (e.g., a person who intrudes out of curiosity or for recreational activities such as hunting) would be lower than the dose to a permanent intruder by two orders of magnitude or more. The results presented in Tables S2.1 and S2.2 are based on a permanent intruder scenario. 
The dominant contributions from exposed FUSRAP wastes are from the plant pathway (ingestion of plant food raised in a garden planted in the waste. field) and the radon inhalation pathway (airborne radon decay products inside a residence located in a contaminated area containing radium). The dose from the plant pathway would be substantially reduced (by a factor of 10 or more) by a cover layer of $2 \mathrm{~m}$ of clean soil; the dose from the radon pathway would be similarly reduced by a layer of $2 \mathrm{~m}$ of clean soil below the floor (which would be 1 to $2 \mathrm{~m}$ below grade level if there were a basement). The contribution from the water pathway (which will, under typical conditions, be much smaller than the plant and radon pathway contributions) would also be reduced by a comparable amount if the cover were clay with a very low hydraulic conductivity. These reductions would, however, continue to be realized only if the cover were maintained to prevent erosion. In order to prevent contamination of the groundwater, it would also be necessary to prevent root penetration and animal burrowing that would otherwise allow water to infiltrate into the wastes.

Under the planned dispersal alternatives, it would be necessary to maintain the site for more than 10,000 years if leaching were the dispersal mechanism utilized and the contamination were from ore or ore-processing residues. The time could be shorter for man-made radionuclides for which leaching from soil material occurs primarily by ion exchange. If dispersal were by erosion, it would be necessary to control and monitor the dispersal until all radionuclides were dispersed. The problems of ensuring that the rate of dispersal did not exceed acceptable limits during the dispersal period would be complex and difficult (and are beyond the scope of this study), but should be considered in the context of the problems of maintaining the integrity of the containment for the duration of the hazard.

For a quantitative comparative assessment, more detailed specification of the alternatives would be needed with regard to the nature of the controls, cover thickness and permeability, and measures to maintain the controls and cover or to control dispersal. However, a ranking of some categories of waste management alternatives with respect to the long-term radiological impacts may be made on the basis of qualitative considerations. This ranking, given in Table S2.3, is based on the considerations given in the following text.

If the alternatives are ranked with respect to the long-term radiological impacts to the maximaliy exposed individual, the no-action alternative would have the greatest impact and has, therefore, been given the lowest ranking. Institutional controls are ranked next lowest. In ranking in-situ stabilization above institutional controls, it is assumed that institutional controls are also imposed. It is also assumed that in-situ stabilization allows for planned, slow dispersal. Comparable institutional controls are postulated for containment with planned dispersal. Containment with planned úispersal is ranked above in-situ stabilization on the assumption that the cover thickness will be greater and that some gain should be realized in the design and (for offsite containment) selection of the site.

The differences in the generic estimates for the long-term radiological impacts to the maximally exposed individual for the remaining containment al ternatives are less than the uncertainties. All containment alternatives that involve more elaborate measures than in-situ stabilization have, therefore, been grouped together and given the same ranking. The long-term radiological impacts for containment without dispersal include the occupational exposure 
Table S2.3. Ranking of Several Categories of Alternatives for Managing FUSRAP Wastes with Respect to Long-Term Radiological Impacts to the Maximally Exposed Individual

\begin{tabular}{|c|c|}
\hline Ranking & Waste Management A1ternative* \\
\hline 1 & Immediate dispersal \\
\hline 2 & Containment (with or without planned slow dispersal) \\
\hline 3 & 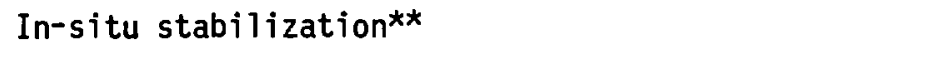 \\
\hline 4 & Institutional controls only \\
\hline 5 & No action \\
\hline
\end{tabular}

*Alternatives are ordered according to long-term radiological impacts to the maximally exposed individual from the smallest radiological impact (immediate dispersal) to the largest radiological impact (no action). Short-term radiological impacts are not included.

**Institutional controls and planned, slow dispersal are assumed for in-situ stabilization.

associated with maintenance activities; this exposure would offsei any public exposure from containment with planned dispersal, and may even resuit in a greater exposure. The long-term dose to the maximally exposed individual for the immediate dispersal al ternative would be an extremely small fraction of the natural background dose. Immediate dispersal has, therefore, been given the highest ranking. The radiological impacts for ocean dispersal are expected to be less than for land dispersal.

The scale for the rankings is not uniform. The largest difference is between no action and institutional controls only; this difference is considered to be significant. The difference between the long-term impacts for the containment and immediate dispersal alternatives is not considered to be significant.

Only the long-term potential dose rates for the maximally exposed individual have been taken into account in determining the rankings (Table S2.3). The short-term potential dose rates will be primarily from the occupational dose. There will be essentially no occupational doses for no action and minimal doses for institutional controls only, and these doses will be less for onsite containment (which includes in-situ stabilization) than for offsite containment. Occupational doses are expected to be comparable for the containment and ocean-dispersal alternatives, and greatest for immediate dispersal onland. Thus, ranking on the basis of occupational dose alone would be the reverse of that given in Table S2.3 for the long-term dose to the maximally exposed individual. 
The population dose is determined by wind and water dispersal of the radionuclides. Preliminary estimates indicate that the population dose within $80 \mathrm{~km}$ of the site would be about $0.01 \%$ of the background dose for exposed waste. The differences in population doses for the different alternatives would result primarily from the time at which they occur; in the long term, they are expected to be the same for the different alternatives within the range of uncertainty with which they may be estimated. 


\section{S3. COST COMPARISONS}

The waste management alternatives defined and discussed in the original version of this study (Sections 1 through 6 of this report--originally presented by Gilbert et al. 1982) have been regrouped into categories in order to simplify the cost comparison. This simplified cost comparison is presented in Table S3.1 (Tables S2.3 and S3.1 supersede Table 5.1 of this report). The highest-cost alternative--containment without future dispersal (see Section 5)-is used as the baseline case. The comparative cost estimates are based on very general considerations.

The short-term costs will obviously be less if the wastes are not removed to another location. The cost difference between containment without dispersal and containment with planned, monitored dispersal is evident only in the long term; in the short term, the costs are the same. Planned, unmonitored dispersal would be used for disposal in deep geologic repositories or containerized ocean disposal, which are obviously more costly. Immediate dispersal would also involve additional facilities and equipment that can be expected to be comparable in cost to containment in the short term.

The long-term costs are determined by the duration and extent of the required surveillance, monitoring, and maintenance. There is no commitment to these future actions for the no-action alternative; for planned, unmonitored dispersal; or for immediate dispersal--the only costs for these alternatives would be short-term costs. The duration of the commitment would be limited for containment with planned, monitored dispersal; the commitment would end when natural dispersal processes had reduced the concentration of the radionuclides in the waste field to acceptable levels for no further action. Furthermore, if the planning and design were adequate, the future commitment might require nothing more than occasional surveillance for obvious changes such as gully erosion or permanent intruder action. Monitoring would be undertaken only if the surveillance indicated the need, and maintenance only if the monitoring revealed that the rate of dispersal was sufficiently above the planned level to constitute a public health hazard. Containment without future dispersal would inevitably require future maintenance as well as a commitment to surveillance and monitoring and, therefore, would be the most costly al ternative. 
Table S3.1. Cost Comparison of Alternatives for Management of FUSRAP Wastes

\begin{tabular}{|c|c|c|c|c|}
\hline \multirow[b]{2}{*}{ Waste Management Alternative } & \multirow[b]{2}{*}{$\begin{array}{l}\text { Future } \\
\text { Commi tment* }\end{array}$} & \multicolumn{3}{|c|}{ Costs } \\
\hline & & $\begin{array}{l}\text { Short- } \\
\text { Term }\end{array}$ & $\begin{array}{l}\text { Long- } \\
\text { Term }\end{array}$ & Total \\
\hline No Action & None & None & None & None \\
\hline Onsite Limited Action** & $S$ & Lower & Lower & Lower \\
\hline \multicolumn{5}{|l|}{ Onsite Containment } \\
\hline Without dispersal & SMM & Lower & Same & Lower \\
\hline Planned, monitored dispersal & $S$ & Lower & Lower & Lower \\
\hline \multicolumn{5}{|l|}{ Offsite Containment } \\
\hline Without dispersal & SilM & \multicolumn{3}{|c|}{----Baseline Case------ } \\
\hline Planned, monitored dispersal & S & Same & Lower & Lower \\
\hline Pianned, unmonitored dispersal & None & Higher & None & Lower \\
\hline Immediate Dispersal & None & Same & None & Lower \\
\hline
\end{tabular}

${ }^{*} S=$ Surveillance, with possible monitoring and maintenance;

SMM = Surveillance, monitoring and maintenance.

**Institutional controls only or in-situ stabilization. 


\section{S4. CONCLUSIONS}

On the basis of the preceding considerations and the comparisons in Tables S2.3 and S3.1, the conclusions may be restated as follows.

- Containment without dispersal appears to be the least attractive alternative because active surveillance, monitoring, and maintenance would be required until the "end of civilization" and the radiological impacts would not be significantly less than for other alternatives.

- Immediate dispersal may be preferable to offsite containment because it results in a comparable or lower radiation dose to the maximally exposed individual in the long term and no surveillance, monitoring, or maintenance is needed.

- Onsite containment with institutional controls only or in-situ stabilization are the most attractive alternatives for many FUSRAP sites because they are the least costiy and can provide adequate protection of public health and safety if the radionuclide concentrations in the FUSRAP wastes are not exceptionally high.

These conclusions are based solely on a comparison of the radiological impacts and costs. They do not take into account land-use agreements, legal necessities, or public attitudes and perceptions--all of which must be weighed in the selection of an appropriate alternative for management of FUSRAP wastes. 


\section{S5. REFERENCES}

Gilbert, T.L., J.M. Peterson, R.W. Vocke, and J.K. Alexander. 1982. Alternatives for Management of Wastes Generated by the Formerly Utilized Sites Remedial Action Program, pp. III-21 to III-36. In Proceedings of the 1982 International Decommissioning Symposium, Seattle, WA, October 10-14, 1982.

Gilbert, T.L., P.C. Chee, M.J. Knight, J.M. Peterson, C.J. Roberts, J.E. Robinson, S.Y.H. Tsai, and Y.C. Yuan. 1983. Pathways Analysis and Radiation Dose Estimates for Radioactive Residues at Formerly Utilized MED/AEC Sites. ORO-832. Prepared for the U.S. Department of Energy, Oak Ridge Operations, Oak Ridge, TN, by the Division of Environmental Impact Studies, Argonne National Laboratory, Argonne, IL.

Knight, M.J. 1982. The Effect of Soil Erosion on the Long-Term Stability of FURSRAP Near-Surface Waste-Burial Sites. ANL/EIS-18. Prepared for the Formerly Utilized Sites Remedial Action Program, U.S. Department of Energy, Oak Ridget Operations, Oak Ridge, TN, by the Division of Environmental Impact Studies, Argonne National Laboratory, Argonne, IL. 
Internal:

E.S. Beckjord

J. Rundo

P.F. Gustafson

W.J. Hallett

C.J. Roberts
J.D. DePue

R.W. Vocke (30;

T.L. Gilbert (10)

J.M. Peterson

D.J. Wyman
ANL Contract File ANL Patent office

ANL Libraries (4)

TIS Files (6)

\section{External:}

DOE-TIC (2)

Manager, Chicago Operations Office, DOE

Keller, E.L., Dak Ridge Operations, DOE, Oak Ridge, TN (6)

Alexander, J.K., Oak Ridge Operations, DOE, Oak Ridge, TN

Review Committee for the Division of Environmental Impact Studies:

Burstein, Mr. Sol, Wiscons in Electric Power Company, Milwaukee Hannon, Or. Bruce M., University of Illinois, Urbana

Moeller, Dr. D.W., Harvard School of Public Health, Boston, MA

Morgan, Dr. M. Granger, Carnegie-Mellon University, Pittsburgh, PA

Wixson, Dr. Bobby G., University of Missouri-Rolla 